Vol.3 No.2 Hal. 62- 68

September 2020

\title{
Penerapan Lesson Study Untuk Meningkatkan Kompetensi Guru di MGMP Biologi Langsa
}

\section{Tri Mustika Sarjani ${ }^{(1)}$, Nursamsu $^{(2)}$}

Program Studi Pendidikan Biologi

Fakultas Keguruan dan Ilmu pendidikan

Universitas Samudra ${ }^{(1)(2)}$

$\underline{\text { sarjani@unsam.ac.id }}^{(1)}$, samsu_bio@unsam.ac.id ${ }^{(2)}$

\begin{abstract}
ABSTRAK
Tujuan penelitian adalah untuk mengetahui seberapa besar Peningkatan Kompetensi Guru MGMP Biologi Langsa Dalam Menerapkan Tahapan Lesson Study. Metode penelitian menggunakan metode Penelitian Tindakan Kelas (PTK). Sampel dalam penelitian ini adalah seluruh guru biologi 30 yang bergabung dengan MGMP Biologi Kota Langsa. Teknik pengunpulan data dalam penelitian berupa yaitu observasi dan berupa soal tes mengenai kemampuan kompetensi pedagogik, profesional, kepribadian dan sosial. Sedangkan teknik analisa data adalah teknik Normalized Gain. Hasil dalam penelitian ini adalah Penerapan pembelajaran lesson study tahap perencanaan (plan) dengan nilai $0,32 \%$ dapat dinyatakan baik, sedangkan pelaksanaan $(d o$ ) nilai yang diperoleh $0,35 \%$ dinyatakan sedang dan refleksi (see) nilai yang diperoleh $0,42 \%$, maka hasil yang diperoleh dari ke tiga pembelajaran lesson study dinyatakan baik untuk diterapkan sebagai proses pembelajaran. Penilaian dari hasil kegiatan ini di ukur peningkatan kompetensi guru yang terdiri dari kompetensi pedagogik, profesional, kepribadian dan sosial, maka dapat disimpulkan terjadi peningkatan dari siklus I dan siklus II.
\end{abstract}

Kata Kunci : Lesson Study, Kompetensi, MGMP Biologi

\begin{abstract}
The research objective was to find out how much the Competence of the Langsa Biology MGMP Teachers in Applying Lesson Study Stages. The research method uses Classroom Action Research (CAR). The sample in this study were all 30 biology teachers who joined the MGMP Biology Langsa City. The data collection techniques in the research were observation and in the form of test questions regarding the ability of pedagogic, professional, personality and social competencies. While the data analysis technique is the Normalized Gain technique. The results in this study are the implementation of lesson study learning in the planning stage (plan) with a value of $0.32 \%$ can be declared good, while implementation (do) the value obtained is $0.35 \%$ stated as moderate and reflection (see) the value obtained is $0.42 \%$, then the results obtained from the three lesson study lessons are stated to be good to be applied as a learning process. The assessment of the results of this activity is measured to increase teacher competence consisting of pedagogical, professional, personal and social competencies, so it can be concluded that there has been an increase from cycle I and cycle II.
\end{abstract}

Keywords : Lesson Study, Competence, Biology MGMP 
Sarjani Tri M, Nursamsu : Penerapan Lesson Study Untuk Meningkatkan Kompetensi Guru di MGMP Biologi Langsa

\section{PENDAHULUAN}

\section{Latar Belakang}

Lesson Study bukan dikatakan suatu metode atau strategi pembelajaran akan tetapi merupakan kegiatan Lesson Study yang dapat menerapkan berbagai dari metode atau strategi pembelajaran yang sesuai dengan suatu situasi dan kondisi serta permasalahan yang dihadapi guru. Sesuai dengan pendapat Sumar Hendayana, dkk (2006) dapat diartikan sebagai suatu model pembinaan profesi pendidik melalui pengkajian pembelajaran secara kolaboratif dan berkelanjutan berlandaskan prinsip-prinsip kolegalitas dan mutual learning untuk membangun komunitas belajar. Lesson study merupakan sebuah pendekatan untuk melakukan perbaikan-perbaikan pada proses pembelajaran (Rokhmawati,2011). Lesson study dapat diartikan sebagai model pembinaan bagi pendidik melalui pengkajian dan perbaikan pembelajaran yang sudah dilakukan agar menjadi lebih baik secara kolaboratif dan berkelanjutan, berdasarkan prinsip-prinsip kesejawatan dan mutul learning untuk membangun komunitas belajar. Perbaikan itu dilakukan dengan berkolaborasi antar para guru, sehingga diharapkan dengan penerapan lesson study akan mampu mengembangkan kegiatan pembelajaran biologi (Susilo, 2013). Sementara Friedkin (2005) mendefinisikan lesson study sebagai proses yang melibatkan guru-guru yang bekerja sama dalam merencanakan, mengobservasi, menganalisis, dan memperbaiki pembelajarannya. mProses pembelajaran Lesson Study dilakukan dalam 3 tahapan yaitu: (1) Plan (Perencanaan) yang mencakup Menganalisis topik, Menganalisis realitas siswa, Membuat Rencana Pembelajaran dan memeriksa Rencana Pembelajaran. (2) Do (Pelaksanaan) yang mencakup tiga langkah, membangkitkan minat siswa, menyadari pembelajaran bermakna bagi siswa, menyimpulkan pelajaran dan (3) See (Refleksi) yang mencakup Merefleksi pelajaran. Hasil dari tahapan "see" akan diberikan kembali pada tahapan "plan" dan "Do" untuk peningkatan pelajaran selanjutnya (Juwairiyah, 2009). Sedana dengan pendapat Isoda (2010) yang menyatakan bahwa kegiatan ilmiah yang dilakukan untuk mengembangkan teori pembelajaran dalam meningkatkan praktek mengajar yang lebih baik dengan menggunakan pembelajaran lesson study. Sedangkan Sukirman (2006) memandang lesson study sebagai model pembinaan profesi pendidik melalui pengkajian pembelajaran secara kolaboratif dan berkelanjutan berdasarkan prinsip- prinsip kolegalitas dan mutual learning untuk membangun learning community. Pembelajaran lesson study dapat meningkatkan profesional guru. Sebagai seorang guru yang profesional tentu harus memenuhi standar kompetensi guru. Permendiknas No. 16 tahun 2007 tentang standar kompetensi guru menjelaskan bahwa kompetensi yang harus dimiliki oleh guru terbagi atas empat kategori, yaitu kompetensi pedagogik, kompetensi kepribadian, kompetensi profesional, dan kompetensi sosial. Lebih lanjut Al-Tabany (2014) menjelaskan bahwa dalam pembelajaran abad 21 bahwasanya sistem pendidikan nasional menghadapi tantangan yang sangat kompleks dalam menyiapkan kualitas sumber daya manusia (SDM) yang mampu bersaing di era global yang berbasis teknologi. Dari itulah dunia pendidikan harus menciptakan pendidik atau guru yang mampu dalam menghadapi tantangan industri 4.0. Pendapat diatas menjelaskan mengenai pembelajaran lesson study dan kompetensi guru maka kami sebagai tim penelitian melakukan observasi awal untuk mengetahui bahwa pembelajaran lesson study ini dapat diterapkan sebagai kegiatan pembelajaran. Ternyata guru biologi yang ada di Kota Langsa belum pernah menerapkan pembelajaran lesson study dalam proses pembelajaran. Bahkan pembelajaran lesson study istilah baru yang mereka dengar. Oleh sebab itulah kami membuat pembelajaran lesson study kepada guru MGMP Biologi Kota Langsa yang dapat meningkatkan kompetensi guru. 
Sarjani Tri M, Nursamsu : Penerapan Lesson Study Untuk Meningkatkan Kompetensi Guru di MGMP Biologi Langsa

\section{Perumusan Masalah}

Pelaksanaan penelitian dilakukan dengan menggunakan siklus penelitian lesson study, karena pembelajaran ini dapat meningkatkan kompetensi guru dalam melaksanakan kegiatan pembelajaran. Adapun yang menjadi permasalahan dalam penelitian yaitu (1) Bagaimana Penerapan Lesson Study Untuk Meningkatkan Kompetensi Guru Di MGMP Biologi Kota Langsa; (2) Seberapa Besar Peningkatan Kompetensi Guru MGMP Biologi Langsa Dalam Menerapkan Tahapan Lesson Study. Proses pelaksanaan kegiatan ini di dukung dengan hasil penelitian Widjajanti (2006), dengan pemahaman bahwa lesson study adalah forum untuk saling belajar dalam upaya mengembangkan kompetensi masing- masing anggota tim, maka semangat dalam tahap refleksi ini adalah secara bersama- sama menemukan solusi untuk masalah yang muncul agar pembelajaran berikutnya dapat dipersiapkan dan dilaksanakan dengan lebih baik.

\section{Tujuan Penelitian}

Dasar dari tujuan penelitian ini adalah untuk mengetahui seberapa besar Peningkatan Kompetensi Guru MGMP Biologi Langsa Dalam Menerapkan Tahapan Lesson Study.

\section{Manfaat Penelitian}

Manfaat yang akan didapat dari penelitian ini adalah berkaitan dengan tujuan dari penelitian ini berhubungan konsep penelitian dengan melaksanakan pembelajaran lesson study menurut Isnandar (2010) menyatakan bahwa dengan adanya pembelajaran Lesson Study, guru dapat mengkolaborasikan dengan ide yang ada untuk menciptakan suatu pembelajaran yang menarik serta inovatif. Sedangkan menurut White \& Lim (2008) lesson study merupakan suatu kegiatan di mana seorang guru dapat mengembangkan proses dengan pengembangan pembelajaran serta keterampilan profesional dalam meningkatkan hasil pembelajaran siswa. Sedangkan menurut Susilo (2006) lesson study dapat diartikan suatu kegiatan pembelajaran yang dilaksanakan oleh guru untuk meningkatkan kualitas pembelajaran dan pengembangan keprofesionalan guru.

\section{METODE PENELITIAN}

Metode penelitian yang digunakan adalah Penelitian Tindakan Kelas (PTK). Sanjaya (2013:150) menjelaskan bahwa tujuan dari metode PTK yaitu "memperbaiki kinerja guru, menumpuhkan sikap profesional guru, dan peningkatan situasi tempat praktik berlangsung. Untuk mengukur pencapaian kompetensi guru dalam pembelajaran tahapan siklus yang akan dilaksanakan pada pembelajaran lesson study terdiri dari perencanaan (plan), pelaksanaan (do) dan refleksi (see). Adapun tahapan rancangan pembelajaran lesson study dalam penelitian terlihat pada gambar dibawah ini.

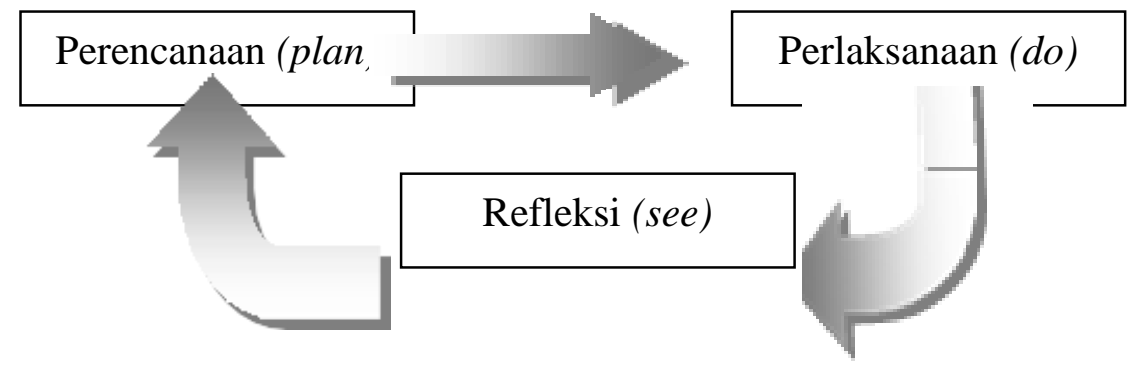

Gambar 1. Tahapan Pembelajaran Lesson stuay 
Sarjani Tri M, Nursamsu : Penerapan Lesson Study Untuk Meningkatkan Kompetensi Guru di MGMP Biologi Langsa

1. Populasi dan Sampel Penelitian

Populasi dalam penelitian ini adalah seluruh guru MGMP Biologi tingkat SMA/SMK sederajat Kota Langsa yang terdiri dari 30 guru mata pelajaran biologi. Sampel dalam penelitian ini adalah diambil keseluruh dari jumlah populasi yang terdiri dari 30 orang guru mata pelajaran biologi yang bergabung dengan MGMP Biologi Kota Langsa. Teknik pengambilan sampel dalam penelitian ini menggunakan teknik purposive sampling.

2. Teknik Pengumpulan Data

Teknik pengunpulan data dalam penelitian berupa yaitu observasi dan berupa soal tes mengenai kemampuan kompetensi pedagogik, profesional, kepribadian dan sosial.

3. Teknik Analisa Data

Teknik analisis data untuk Penelitian Tindakan Kelas (PTK) dilakukan melalui tiga tahap yaitu reduksi data, paparan data, dan penyimpulan (Muslich,2012:52). Sedangkan untuk mengetahui peningkatan kompetensi guru yaitu dihitung menggunakan teknik Normalized Gain dihitung dengan rumus:

$$
N \text { Gain }=\frac{\text { Skor Posttest }- \text { Skor Pretest }}{\text { Skor Ideal }- \text { Skor Pretest }}
$$

Skala nilai yang digunakan pada data $\mathrm{N}$-gain terdapat pada tabel di bawah ini:

Tabel 1. Kriteria Normalized Gain

\begin{tabular}{|c|c|}
\hline Nilai N-Gain & Kategori \\
\hline $\mathrm{g}>0,7$ & Tinggi \\
\hline $0,3 \leq \mathrm{g} \leq 0,7$ & Sedang \\
\hline $\mathrm{g}<0,3$ & Rendah \\
\hline
\end{tabular}

Sumber: (Hake, 1998)

\section{HASIL DAN PEMBAHASAN \\ Hasil Penelitian}

Hasil dari Pelaksanaan kegiatan penelitian mengenai pembelajaran lesson study yang dilaksanakan oleh tim penelitian di MGMP Biologi Kota Langsa. Dimana pembelajaran lesson study diterapkan kepada guru mata pelajaran biologi dengan tahapan pembelajaran lesson study yang terdiri dari tiga tahapan sebagai berikut.

\section{a. Tahap I Perencanaan (Plan)}

Pada tahap ini tim penelitian sebagai observer menjelaskan dan musyawarah kepada guru yang menerapkan pembelajaran lesson study. Tahap ini dilakukan dengan tahapan perencanaan (plan), dimana tahap ini mempersiapkan prangkat pembelajaran seperti silabus, RPP, model dan media pembelajaran yang akan disajikan untuk kegiatan pembelajaran.

\section{b. Tahap II Pelaksanaan (do)}

Pada tahap pelaksanaan (do) guru model menerima dari kekurangan pembelajaran lesson study yang dilaksanakan pada siklus I serta memperbaiki dari kekurangan tersebut dan dilaksanakan pada siklus II.

\section{Tahap III Refleksi (see)}

Pada tahap kegiatan refleksi (see) guru model mengevaluasi hasil kegiatan pada tahap perencanaan dan pelaksanaan, jika pelaksanaan ada kelemahan dan kekurang di tahap ini maka menjadi suatu acuan untuk diperbaiki serta sebagai pedoman untuk pembelajaran selanjutnya. Hasil dari tahapan pembelajaran lesson study terdapat pada gambar di bawah ini. 
Sarjani Tri M, Nursamsu : Penerapan Lesson Study Untuk Meningkatkan Kompetensi Guru di MGMP Biologi Langsa

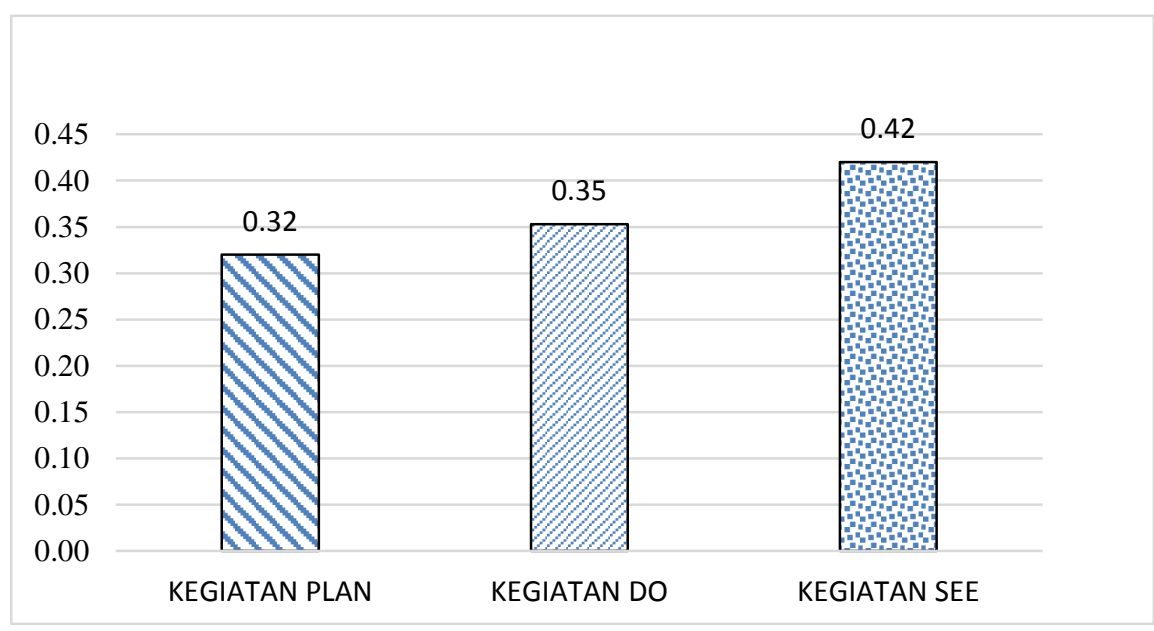

Gambar 2. Nilai Rata - Rata Pembelajaran Lesson Study

\section{d. Pengukuran Kompetensi Guru}

Setelah pelaksanaan pembelajaran lesson study maka akan dilakukan proses pengukuran kemampuan kompetensi guru yang terdapat pada gambar di bawah ini.

Siklus I Pelaksanaan pada siklus I dilakukan terlebih dahulu tes awal kepada guru MGMP Biologi Kota Langsa. Tahap siklus I guru dan observer berdiskusi sistem pelaksanaan pembelajaran lesson study serta materi pembelajaran. Tujuan dari tahap ini untuk mengetahui seberapa besar kemampuan kompetensi guru MGMP Biologi Kota langsa memahami mengenai pembelajaran lesson study. Adapun hasil yang diperoleh terdapat pada gambar sebagai berikut.

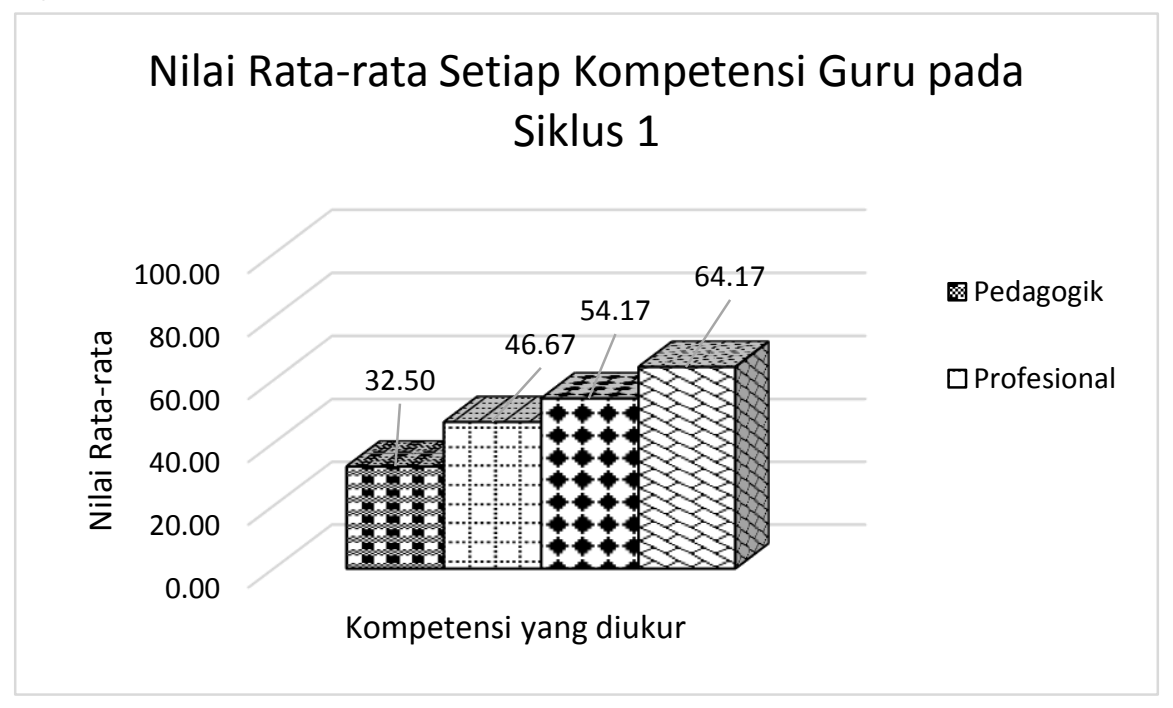

Gambar 3. Nilai Rata - Rata Silus ISiklus II

Pelaksanaan pada siklus II dilakukan setelah guru melaksanakan pembelajaran lesson study. Dimana guru dan obsever berdiskusi kekurangan dari siklus I untuk di revisi. Data yang didapat pada siklus II dapat dilihat pada gambar dibawah ini. 
Sarjani Tri M, Nursamsu : Penerapan Lesson Study Untuk Meningkatkan Kompetensi Guru di MGMP Biologi Langsa

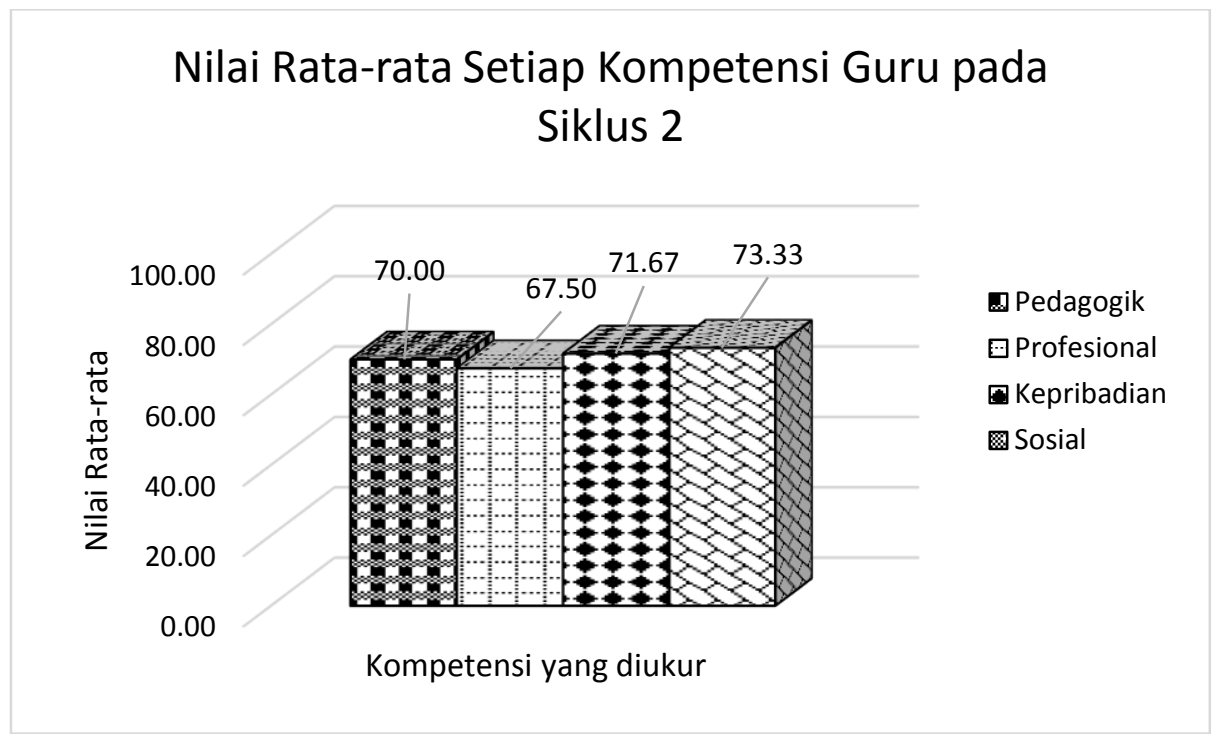

Gambar 4. Nilai Rata - Rata Silus II

\section{PEMBAHASAN}

Berkenaan dengan pendapat hasil dari penelitian diatas maka menurut Nudji (2014) yang menyatakan bahwa lesson study dapat meningkatkan kemandirian belajar mahasiswa. Menurut Rozak \& Fauziah (2013) menyatakan Implementasi lesson study berdampak positif bagi pembinaan dan peningkatan kompetensi pedadogik guru bahasa Indonesia. Sedangkan menurut farida, A (2016) menyatakan melalui lesson study dosen matematika inilah diharapkan dapat meningkatkan kinerja dosen dan akhirnya berdampak pada kualitas pembelajaran dan mahasiswa. Selanjutnya berhubungan dengan hasil penelitian Nursamsu, dkk (2018) menunjukkan bahwa pada siklus I dengan menggunakan proses kegiatan lesson study pada tahap perencanaan (plan), pelaksanaan (do) dan refleksi (see) dengan nilai $81,66 \%$ yang dikatagorikan baik. Hasil penelitian pada siklus II dengan menggunakan proses kegiatan lesson study pada tahap perencanaan (plan), pelaksanaan (do) dan refleksi (see) menunjukkan nilai $89,58 \%$ yang dikatagorikan baik.

\section{KESIMPULAN}

Adapun yang menjadi kesimpulan dalam penelitian ini yaitu.

1. Penerapan pembelajaran lesson study tahap perencanaan (plan) dengan nilai $0,32 \%$ dapat dinyatakan baik, sedangkan pelaksanaan (do) nilai yang diperoleh $0,35 \%$ dinyatakan sedang dan refleksi (see) nilai yang diperoleh $0,42 \%$, maka hasil yang diperoleh dari ke tiga pembelajaran lesson study dinyatakan baik untuk diterapkan sebagai proses pembelajaran.

2. Penilaian dari hasil kegiatan ini di ukur peningkatan kompetensi guru yang terdiri dari kompetensi pedagogik, profesional, kepribadian dan sosial, maka dapat disimpulkan terjadi peningkatan dari siklus I dan siklus II.

\section{DAFTAR PUSTAKA}

Al-Tabany, Trianto , (2014) , Mendesain Model Pembelajaran Inovatif, Progresif dan Kontekstual, Jakarta: Kencana.

Friedkin, Shelley (2005) What is Lesson Study?. [Online]. Tersedia: http://www.lessonresearch.net/ . [29 Juli 2020]. 
Sarjani Tri M, Nursamsu : Penerapan Lesson Study Untuk Meningkatkan Kompetensi Guru di MGMP Biologi Langsa

Fraenkel, Jack R. 2008. How to Design and Evaluate Research in Education 7th Edition, New York: McGraw-Hill.

Farida, A. (2016). Implementasi Lesson Study Untuk Meningkatkan Kinerja Dosen Matematika STMIK Duta Bangsa Surakarta. Jurnal Derivat, 3(2), 17-24.

Hendayana,S., dkk. 2006. Lesson Study: Suatu Strategi Untuk Meningkatkan Keprofesionalan Pendidik (pengalaman IMSTEP-JICA).

Hake, R.R. 1998. Interactive engagement v.s traditional methods: six- thousand student survey of mechanics test data for introductory physics courses. American Journal of Physics. Vol. 66. No.1.

Juwairiyah, 2009. Profesionalisme Guru melalui Lesson Study. http://sumut.kemenag.go.id. Diunduh tanggal 10 Agustus 2019.

Isoda,M. 2010. Lesson Study: Problem solving Approaches in Mathematics Education as Japanese Experiences. http//doi:10.1016/j.sbspro.2010.12.003. Diunduh tanggal 19 Maret 2020.

Nudji, D. A. (2014). Upaya Meningkatkan Kemandirian Belajar Mahasiswa PPKN Melalui Pembelajaran Lesson Study. Jurnal Heritage, 2(2), 9-18.

Nuursamsu, dkk. (2018). Aplikasi Lesson Study dalam Meningkatkan Kompetensi Profesional Guru di Madrasah Aliyah Bustanul Ulum Kota Langsa. Jurnal Pendidikan Biologi 8 (1), 14 - 19.

Permendiknas No. 16 Tahun 2007 Tentang Standar Kompetensi Guru

Rokhmawati, A. (2011). Implementasi Praktik Pengalaman Lapangan (PPL) Berbasis Lesson Study untuk Meningkatkan Keterampilan Mahasiswa Pendidikan Biologi FMIPA UM dalam Memanfaatkan Media Pembelajaran dan Hasil Belajar Biologi Siswa SMA Negeri 9 Malang. Skripsi, Program Studi Pendidikan Biologi, Jurusan Biologi, Universitas Negeri Malang.

Rozak, A., \& Fauziah, E. (2013). Implementasi lesson study sebagai upaya peningkatan kompetensi pedagogik guru bahasa indonesia di SMP kabupaten Cirebon. Jurnal Pendidikan Bahasa dan Sastra, 13(1), 1-11.

Susilo, H. (2006). Apa dan Mengapa Lesson Study Perlu Dilakukan untuk Meningkatkan Profesionalisme Guru dan Dosen MIPA. In Makalah. Disajikan dalam Seminar Peningkatan Profesionalisme Guru dan Dosen MIPA melalui Lesson Study, di Singaraja (Vol. 25).

Sukirman. (2006). Peningkatan Profesionalisme Guru Melalui Lesson Study. Makalah Disampaikan Pada Kegiatan Pelatihan 2 Hari untuk Fasilitator dan Tim TPK SISTTEMS Bantul Emergency Program Pada 29 Juli 2020.

Santrock, John W.2009. Educational Psychology 4th Edition. New York: McGraw-Hill.

Susilo, H. (2013). Lesson Study Sebagai Sarana Meningkatkan Kompetensi Pendidik. Disajikan dalam Seminar dan Lokakarya PLEASE 2013 di Sekolah Tinggi Theologi Aletheia Jalan Argopuro 28-34 Lawang, Tanggal 9 Juli 2013.

Widjajanti, D.B. (2006). Pengembangan Kompetensi Guru Matematika Melalui Lesson Study. Makalah disampaikan pada Seminar Nasional dan Konferensi Nasional Matematika di Universitas Negeri Semarang pada 30 Juli 2020.

White, A. L., \& Lim, C. S. (2008). Lesson study in Asia Pacific classrooms: Local responses to a global movement. ZDM, 40(6), 915-925

\begin{tabular}{|l|l|l|l|}
\hline Accepted Date & Revised Date & Decided Date & Accepted to Publish \\
\hline 30 Juli 2020 & 04 Agustus 2020 & 11 Agustus 2020 & Ya \\
\hline
\end{tabular}

